[Glynn, T., Berryman, M., Atvars, K., Harawira, W., Walker, R., \& Kaiwai, H. (1998). Bicultural Research and Support Programmes for Maori Students, Teachers and Communities. New Zealand Annual Review of Education, 7, 111-132]

\section{Bicultural Research and Support Programmes for Maori Students, Teachers and Communities}

\author{
TED GLYNN, MERE BERRYMAN, KATHRYN ATVARS, \\ WAI HARAWIRA, RANGIWHAKAEHU WALKER AND HONE \\ KAIWAI
}

\section{Abstract:}

This paper highlights the importance of majority-culture professionals learning to work in contexts where control over educational research, development and training for indigenous people remains under the control of indigenous people, and is located within culturally preferred practices and settings.

We describe work undertaken by our bicultural research whanau at the New Zealand Specialist Education Services Poutama Pounamu Education Research Centre, in Tauranga. We discuss processes and outcomes of research which has been undertaken within a research whanau (metaphoric extended family). Our whanau includes Maori elders, Maori members of the New Zealand Specialist Education Services, Maori teachers, as well as Maori students and a non-Maori academic.

To date, our research has focussed on developing and trialing learning and behavioural resources for Maori students, and their teachers and families. We present information from five projects, (1) parent-or peer-delivered Maori and English reading tutoring strategies (Tatari Tautoko Tauawhi); (2) a collaborative parent and teacher programme designed to assist Maori students experiencing behavioural difficulties in school, home and community settings (Hei Āwhina Mātua); (3) a programme for improving students' learning to write in Maori (Kia Puawai ai Te Reo); (4) a study of the training needs of itinerant Resource Teachers of Guidance and Learning, so they can assist Maori students experiencing behavioural and learning difficulties in mainstream schools; and (5) Mauri Tau, a programme for young Maori who are parents or are becoming parents.

\section{Ted Glynn et al.}

Each of the five projects has generated practical and effective resources for sharing with Maori students, teachers and communities. We now seek to establish networks to enable us to deliver our research findings and materials around New Zealand. We conclude this paper by focussing attention onto some of the important cultural principles which have guided our work, and will continue to do so.

\section{Indigenous Rights To Language And Cultural Maintenance}

Indigenous people have the right to all levels and forms of education. They also have the right to establish and control their educational systems and institutions, providing education in their own language. (Article 14, The Coolongatta Statement on Indigenous Rights in Education, 1993)

The Coolongatta Statement (1993) notes that indigenous peoples across the world are demanding, and achieving, the establishment of systems of education which reflect, respect and embrace indigenous cultural values, philosophies and ideologies; the same values, philosophies and ideologies which have shaped, nurtured and sustained indigenous peoples for tens of thousands of years. The Coolongatta Statement also notes that one of the greatest challenges confronting indigenous peoples in the final years of the twentieth century is how to promote, protect and nurture indigenous cultures in an ever-changing modern society.

In 1840, Lieutenant-Governor Hobson and Maori chiefs signed the Treaty of Waitangi on behalf of the British Crown and the Maori people and their descendants. Under article one of this Treaty, Maori ceded governorship or administrative control (kawanatanga) to the Crown. Under article two, the Crown ceded to Maori chiefly control (tino rangatiratanga) or self-determination over their lands, forests and fisheries and other treasures or resources (taonga). Maori also retained their sovereign rights to define, promote and control those treasures and resources. This included specifically the creation, retention and transmission of language and cultural knowledge. Under article three of the Treaty, Maori were guaranteed the full rights of British citizenship. Maori have long regarded the Treaty of Waitangi as a charter for power sharing in the decision-making processes of government, for self determination as indigenous people, and as a guide to intercultural relations within New Zealand. 
However, the history of the relationship between Maori and European people in New Zealand (Pakeha) has not been characterised by partnership and Maori self-determination, but rather by political and social domination by the Pakeha majority. This history has progressed through armed struggle, biased legislation and successive educational policies and initiatives that have imposed Pakeha language and knowledge codes at the expense of Maori (Bishop \& Glynn, 1997a). Central government educational policies have ranged through Assimilation, Integration, Multiculturalism and Biculturalism. The cumulative effects of these successive policies have been to require Maori to sacrifice more and more of their language, culture and their own indigenous educational aspirations to the needs and goals of the nation, as determined largely by the Pakeha majority. Participation in mainstream education in New Zealand has come for Maori at a cost of their own language and culture.

It is therefore ironic that New Zealand teachers, educators, boards and communities are acknowledging increasingly that recent refugees and economic migrants are entitled to have their language and cultural practices recognised within our schools (Holmes, 1990; Wong-Fillmore, 1991). Instruction via the medium of students' first language, and valuing of students' cultural differences are seen as crucial for the educational and psychological well-being of individual students and their families, and consequently for the well-being of the host society. Yet those same New Zealand teachers, educators, boards and communities are slower to recognise that the language and cultural practices of indigenous Maori people are just as crucial as those of refugee and migrant groups, and for the same reasons.

However, it is not just teachers, educators, boards and communities who are undermining indigenous languages and cultures. Many of us who are educational researchers and trainers like to think that we gather information which will inform educational policy, and persuade administrators to improve educational practice. Yet many of the research and training contexts we create do not allow indigenous people to participate from within their own world view and do not allow indigenous voices to be heard.

Within many mainstream educational research and training contexts, indigenous people are still regarded as distanced "others" rather than as autonomous partners. This has certainly been the case untilvery recently for educational research in New Zealand. Non-Maori researchers have retained ownership and control of the research questions, the research methods, and the training agenda, as well as how and where that research will be presented and used. Non-Maori researchers have valued and respected, for example, the superiority of information transmitted through writing over information transmitted orally, while the reverse may be true for many Maori people. Maori peoples' experiences, understandings, and evaluations of the reliability and validity of the two means of transmitting information, as well as their preferred learning contexts and learning styles may be quite different from those of non-Maori (Glynn \& Bishop, 1995).

If researchers do not test their understanding against indigenous peoples' understanding of research, they run the risk of continuing to impose their knowledge bases and pedagogical preferences on indigenous people. The process of cultural and linguistic colonisation will continue inexorably. For example, majority culture values of individual achievement and individual responsibility for learning will continue to over-ride and marginalise values of collective achievement and collective responsibility for the wellbeing of the whanau (extended family) or work group. Similarly, majority culture expectations for people to identify themselves as individuals will marginalise Maori expectations for people to identify themselves collectively, in terms of their relationship to their land (whenua) and to their canoe (waka) and their tribes (iwi) and sub-tribes (hapu).

Maori resistance to Pakeha social, cultural, economic, political and legislative domination over the 158 years since the Treaty of Waitangi has been strong and continuous. It has been focussed within a critical perspective described as kaupapa Maori, a grass roots theory of social change and resistance, "the Maori way of doing things; Maori control; Maori autonomy" (Smith, 1990). Smith (1995) notes that kaupapa Maori is at the same time both a proactive "self determination initiative" concerned for language and cultural survival, and simultaneously a "reactive resistance initiative" concerned to respond to Pakeha social, cultural, economic and political domination. While certainly not confined to the sphere of education, kaupapa Maori initiatives have enjoyed a very high profile in New Zealand education since the first Maori language nests (kohanga reo) appeared in 1982. Contemporary Maori education initiatives include well over 800 language nests, approximately 40 Maori immersion primary schools (kura kaupapa Maori), four Maori medium secondary schools (whare kura), as well as three Maori tertiary institutions (whare wananga). 


\section{Kaupapa Maori Research}

Maori resistance to the imposition of Western European perspectives and practices in educational research has also emerged. Kaupapa Maori approaches to educational research acknowledge that Maori means of accessing, defining and protecting knowledge existed before European contact (Bishop, 1996a). Kaupapa Maori research is currently being revitalised and legitimated within the Maori community, in terms of Maori preferred cultural values and practices. These values and practices are expressed through concepts and ideas carried through the Maori language and culture. Concepts such as legitimation and authority (mana), spirituality (wairua), family relationships (whanaungatanga), genealogy (whakapapa), and ancestral traditions (taonga tuku iho) permeate Maori approaches to educational research.

From a kaupapa Maori point of view, ownership and control over the entire research and training process, from framing research questions and selecting appropriate paradigms and methodologies, to presentation and dissemination of information is located within Maori cultural perspectives. Bishop (1996a) suggests that within a kaupapa Maori framework, groups constituted as whanau (a metaphoric use of the concept of extended family, also described as whanau-of-interest) can attempt to develop relationships and patterns of organisation similar to those applying within a traditional Maori whanau. The whanau-of-interest affirms the cultural identity and validates the culturally appropriate processes (tikanga) followed by its members, and hence facilitates the engagement and commitment of Maori professionals, elders and students.

Bishop (1996b) considers that the whanau-of-interest also provides one effective means by which non-Maori researchers can engage safely in research in the Maori world without adopting a controlling, empowering or a liberating position, and yet also without being left to take up an "outsider" position as a consultant or adviser. However, non-Maori need to seek inclusion in a whanau-of-interest in terms of their being able to take up relationships and obligations to other whanau members, elders, adults and children. Non-Maori researchers and trainers need to be able to engage themselves within a whanau-of-interest in terms of Maori-constituted practices and cultural understandings. They need a sufficient grasp of the language and culture to be able to operate comfortably within a Maori world view, encompassing Maori cultural concepts, metaphors, ideas, spirituality and practices. In short, they need to be able to live and experience the world from within a Maori frame of reference (Bishop \& Glynn, 1997a; 1997b).

Research questions about Maori performance and achievement, generated from non-Maori cultural perspectives, have resulted in harmful distortions or over-simplifications of Maori history, Maori culture and, in particular, Maori perspectives on learning and teaching (Bishop \& Glynn, 1992). These distortions and over-simplifications have lent support for majority culture education professionals (e.g., Lovegrove, 1966) to invoke deficit models to explain under-achievement by Maori students. Deficit models seek to account for underachievement in terms of perceived deficiencies in students' family, social and cultural backgrounds, requiring students to undergo more intensive remedial programmes. However, uncritical implementation of such "remedial" programmes may undermine the capacity of minority cultural groups to maintain their own language and culture. This is likely to have a further negative impact on achievement (Wong-Fillmore, 1991).

It is not surprising that such research has been slow to engage the interest of Maori educators, and slow to contribute to the learning of Maori children. Bishop and Glynn (1997b) argue that these problems have arisen because researchers have neglected to address issues of locus and power, control and ownership. So long as ownership and control of the research remains with the researcher, research questions and research processes preferred by Maori may continue to be ignored. These issues of power, control and ownership can be summarised as a series of critical questions for researchers to address (Bishop, 1996a).

Initiation: Whose concerns, interests and research methods determine the design and conduct of the research? Traditionally, educational research has been initiated and participants accessed in ways that are located within Western European cultural concerns, preferences and practices.

Benefits: Who will gain from the research? Research participants do not always benefit from research projects. Research has often served to advance the interests, concerns and methodologies of researchers, and benefits have been located within the researchers' cultural perspectives. This has not worked well for the betterment of Maori in mainstream education.

Representation: Whose life experiences and social reality is depicted in the research, and with whose authority? Traditionally, research has 
misrepresented Maori knowledge and denied the authenticity of Maori experience and voice.

Legitimacy: Whose authority is claimed for research texts? Traditionally, research has undervalued and belittled Maori knowledge and learning practices, and imposed positions and practices that deny the legitimacy of a Maori world view.

Accountability: Who are the researchers accountable to? Who controls the initiation, procedure, construction and evaluation of knowledge generated by the research? Traditionally, Western researchers have insisted on interpreting and expressing the meaning of findings in terms of criteria acceptable within a Western world view.

As noted above, within a kaupapa Maori framework research groups constituted as whanau can form relationships and patterns of organisation similar to those applying within a traditional kinship whanau (Bishop, 1996a). One such research whanau has been established, based on the Specialist Education Service Poutama Pounamu Education Research Centre in Tauranga (Harawira et al., 1996). This research whanau has taken up some of the pedagogical and research challenges presented earlier. We present five examples of research projects which focus on improving the achievement of Maori students, but which also respect the cultural identity, preferred tikanga (culturally appropriate processes) and the tino rangatiratanga of its members.

\section{Poutama Pounamu Research Centre: Ongoing Projects}

\section{Tatari Tautoko Tauawhi Reading Tutoring}

Tatari Tautoko Tauawhi is a set of one-to-one oral reading tutoring procedures to assist students experiencing difficulties in learning to read in Maori. These procedures were derived from the Mangere Home and School Reading procedures developed in previous research in South Auckland (Glynn, McNaughton, Robinson, \& Quinn, 1979). They are currently known as Pause Prompt Praise (Glynn, 1995).

The research whanau conducted an initial ten-week trial of the Tatari Tautoko Tauawhi procedures in a peer-tutoring context with seven tuakana-teina (tutor-tutee) pairs in the Maori medium classes at Maungatapu primary school (Glynn, Atvars, Furlong \& Teddy, 1993; Glynn, Atvars, Furlong, Davies, Rogers \& Teddy, 1993). From a Maori perspective, the tuakana-teina relationship carries with it more than just the connotation of peer tutoring or buddy support. It also carries cultural meanings to do with the relationship of an elder sibling towards a younger sibling, including the rights and responsibilities that each has towards the other within a kinship whanau. Tutoring sessions lasted 15 minutes, three times a week.

Tuakana readily learned to implement the Tatari Tautoko Tauawhi procedures. Following training, tuakana greatly increased their use of Tatari (pausing), and increased their use of Tauawhi (specific praise), although this was already considerable. Tuakana also increased their use of Tautoko (prompting) and reduced their reliance on simply telling tutees the correct word.

At the end of the trial, teina (tutees) increased their correct reading rate from 38 to 43 words per minute, and decreased their incorrect reading rate from 2.4 to 1.8 words per minute. Teina also self corrected more of their errors following the training of their tuakana in Tatari Tautoko Tauawhi. Tuakana, who in their own reading were already displaying higher correct rates than teina, did not further increase this. However, like their teina, tuakana reduced their incorrect reading rate, from 1.6 to 0.6 words per minute. These results were consistent with those from previous research studies reporting gains for tutors as well as tutees in English language peer-tutored reading contexts (Limbrick, McNaughton \& Glynn, 1985; Wheldall \& Mettem, 1985; Glynn \& Glynn, 1986; Medcalf \& Glynn 1987; Tavener \& Glynn, 1989; Tang \& Moore, 1992; Houghton \& Glynn, 1993).

While these results were encouraging, two issues emerged which were not addressed in the trial. First, a number of Maori parents and teachers were concerned about possible negative impact of these gains on their children's learning to read in English. Second, while assessing reading accuracy, self-correction, and correct and incorrect reading rates, the trial did not include measures of reading comprehension.

A second study was implemented at Mount Maunganui Intermediate school, to build on the findings from the Maungatapu study. This study monitored the reading progress in both Maori and English of 26 tuakana-teina (tutor-tutee) pairs and eight control students in Maori medium classes (Glynn, Berryman, Bidois, Walker, Furlong \& Atvars, 1996).

Teina (tutee) students gained between 1.5 and 2.0 years in reading level, increased their correct reading rate by 15 words per minute and lowered their incorrect rate by almost two words per minute. Teina students also increased their comprehension scores by between 20 and 
46 percent. Tuakana (tutor) students also benefited from participating in the tutoring role. They gained between 0.5 and 1.3 years in reading level, increased their correct reading rate by 7 words per minute, and lowered their incorrect rate by 0.8 words per minute. They also increased their comprehension scores by between 19 and 41 percent.

In this study all students read exclusively Maori language texts, and the Tatari Tautoko Tauawhi procedures were implemented predominantly in Maori, yet gains were made by both teina and tuakana on measures of reading in English. Teina gained 1.0 year in English reading level and 20 percent in English comprehension. Tuakana gained 0.5 years in reading level and 25 percent in comprehension. Important cultural learning also took place. Students learned to understand and value the tuakana-teina relationship and its two-way responsibilities, thus highlighting the inseparable linkages between language learning and cultural learning.

While Tatari Tautoko Tauawhi strategies have proved to be highly effective for Maori students learning to read in Maori medium classrooms, the great majority of Maori students are in mainstream classes, and many of them require additional support when learning to read in English. Our research whanau decided to train volunteer adults, many of them grandparents, who were members of Ngai Te Rangi Iwi Social Services and the Maori Women's Welfare League, to tutor low progress Maori students using the English language Pause Prompt Praise reading tutoring strategies. These senior Maori women were matched with individual Maori students. Being able to relate to their readers from within a Maori cultural perspective enabled the women to establish and strengthen their whanau connections with the students, as well as to implement the Tatari Tautoko Tauawhi strategies. This ensured that the readers were working within a responsive, social, learning context (Glynn, 1985), that was also culturally safe. Positive reading gains were made by all the students in this study and these have been reported to the Ministry of Education.

Following this report, the Ministry of Education contracted the Poutama Pounamu Research Centre to deliver and monitor training in Pause Prompt Praise to six coordinators and 12 teachers from three different regions. This was part of the School Community Iwi Liaison Project (Atvars, Berryman, Glynn \& Harawira, 1997). The coordinators and teachers in turn trained Maori whanau members as tutors to implement the reading tutoring procedures. Community trained Pause Prompt Praise reading tutors worked with 227 Maori students from Year
3 to Year 10. Together they participated in ten weeks of reading tutoring. Two hundred and twenty three $(98 \%)$ of these students made measurable gains in reading accuracy, reading comprehension and book level.

\section{Hei whina M tua}

Hei Āwhina Mātua is a whanau-based project which addresses behavioural and learning difficulties experienced by Maori students at home and at school (Glynn, Berryman, Atvars \& Harawira, 1997). Tino rangatiratanga was recognised through our research whanau dealing with Bishop's critical questions of ownership and control within a Maori cultural context (Bishop, 1996a). Design and implementation of the project involved kaumatua and kuia, parents, whanau and teachers from three schools in Tauranga Moana, all of whom have a strong commitment to Maori medium education.

In the first phase of Hei Āwhina Mātua, students, parents, and teachers recorded and prioritised behavioural and learning difficulties and the home and school contexts and settings in which they occur, using three behaviour checklists prepared in both Maori and English (Glynn, Berryman, Harawira, Bidois, \& Atvars, 1997). From the behaviour checklist data it was clear that both whanau members and students agreed that arguing and fighting with brothers and sisters were the top ranked items. Other problem behaviour items shared between student and whanau member lists, were shouting and yelling, not listening, teasing, taunting, not following instructions, tantrums, "packing a sad" and hitting. These were clearly related to arguing and fighting with siblings. The findings provided a strong focus for the home setting skits on the Hei Āwhina Mātua video.

Students and teachers also gave high ratings to school sports, fitness, playtime, and other outside activities, as contexts in which problem behaviours occurred. These data suggested supervision of playground and sporting activities were concerns that teachers needed to address. They also identified a need for skills on the part of students and teachers in negotiating and following rules for playground games. Two behaviour skits were developed around these concerns, and ways to resolve them.

While we had planned extensive consultation with students in this project, we were surprised and delighted when the students themselves sought and provided valuable input into the project at various stages (Glynn, Berryman, Bidois, Atvars, Duffull \& Horne, 1997). Students 
contributed to writing behavioural checklists and assisted in prioritising behaviours and settings of greatest concern. They wrote and acted in eleven video skits which portrayed those behaviours and the home, school and community settings in which they occurred. They assisted in producing and directing the video skits, which present parents and teachers with constructive ways of responding to student behaviour. Some students joined with the research whanau to present a progress report to the Ministry of Education and travelled to Dunedin to help edit the video. It is clear from their own comments that the students had a firm grasp of the purpose of producing the video skits, and of their role in the process:

The teachers thought that if they had written the scripts themselves nobody would have believed what was happening. We all agreed. It would have seemed that we were just kids doing a video because we had to, and we didn't know what we were doing. I thought it was good for us that way. (Bronwyn, 12 years)

We went through the skits and were told we were allowed to have a say in writing any of the scripts. I thought that was neat because we had people my age saying how people my age are talking. Not people the teachers' ages saying what they would have said when they were as young as us. (Troy, 13 years)

The students took control and moved the project from one of management of student behaviour by teachers and whanau to one which incorporated student self-management strategies. Students discussed ways of coping with peer pressure urging them to steal from the local shopping centre, which was one of the challenging contexts they opted to include in the video. They decided that the best strategy to employ in this situation was to choose carefully which friends to go with before entering the shopping centre and then to enlist their help in saying "no" to invitations from others to steal. Self-managed behaviour change strategies are likely to be more effective in the first instance, as well as more enduring in the longer term.

After the Hei Āwhina Mātua video was completed, we developed an accompanying trainer's manual. The manual and video were then trialed within marae-based professional development workshops for Maori teachers and parents from two Maori medium schools. Both schools were working under extraordinary limitations at this time. There was only one permanent teacher (year 2) out of four teachers in one school, and only two out of the three teachers in the other school were permanent. Other teaching staff consisted of a series of long- term relievers, including a relieving principal in one school. Both schools had major and continuing needs for staff development in all areas of the curriculum, and for assistance in implementing positive and culturally appropriate behaviour management strategies. Both schools were struggling to provide support for several inexperienced trainee teachers.

The Hei Āwhina Mātua programme had to be designed and implemented so as to address all of these needs. The programme had to provide a great deal of teacher support with curriculum delivery, assessment strategies and in the establishment of a collaborative working relationship between teachers and whanau members. This high level of support proved to be a necessary and essential component of the implementation of the programme in both schools. With this level of support, Hei Āwhina Mātua was able to assist teachers in both schools to establish positive student behaviour management strategies, and to modify their approaches to presenting and assessing their reading and writing programmes. Hei Āwhina Mātua also enabled teachers to participate with parents and whanau in marae-based workshops on managing student behaviour at home and school. Parents who had attended these workshops reported that the Hei Āwhina Màtua behaviour management strategies had been useful in helping them to positively address behavioural problems at home.

Data from the project (Glynn, Berryman, Atvars \& Harawira, 1997). demonstrated considerable gains in "on-task" behaviour in the classroom and on the playground, as well as in reading and writing, by the 12 target students across the two schools over the six month pre- to post-intervention period. Although most of the 12 target students displayed pre-intervention levels of on-task behaviour that were well below the average levels for their class, all made gains between pre-and post-intervention, some reaching post-intervention levels as high as 90 percent or better. The classroom average on task behaviour levels increased between pre- and post-intervention for all seven classes. In two of these classes the gains were quite major, rising from 43 percent to 86 percent, and 68 percent to 93 percent. This speaks very well of teacher implementation of the Hei Āwhina Mātua behavioural strategies in their classrooms.

Target students in all classrooms in both schools displayed reading gains. Seven students made gains in terms of the level of difficulty of reading book they could read at an accuracy level of at least 90 percent. Gains ranged from one to three book levels. These students also 
displayed improvements in correct reading rate, incorrect reading rate, reading accuracy and comprehension. Five students were reading at an emergent or developing fluency stage and so did not move to a more difficult book level. Nevertheless these students showed gains in correct reading rate, reading accuracy and self-correction rate, as well as in comprehension.

Nine target students in both schools displayed writing gains on both quantitative measures (correct and incorrect writing rates) as well as on qualitative assessments of audience impact and Maori language competence. Three students who were not able to write independently at pre-intervention and for whom it was not possible to obtain rate measures, were all writing independently at the post-intervention stage.

That Hei Āwhina Mātua was able to demonstrate improved student behaviour and learning outcomes, over a six month period in schools working under the severe limitations noted above, indicates that the programme holds considerable promise for achieving positive outcomes for Maori students in other schools, whether Maori medium or mainstream. Our experience in the development and trialing of Hei Āwhina Mātua in this research project has convinced us of the critical need to incorporate a school-wide approach which addresses three components of professional development: curriculumimplementation; assessment; and positive, culturally a ppropriate behaviour management strategies.

\section{Kia Puawai ai te Reo}

Kia Puawai ai te Reo comprises a video and accompanying training and assessment resources to support teachers and parents in improving students' writing in Maori. It was developed and trialed at Mount Maunganui Intermediate, Matapihi and Maungatapu primary schools and Mount Maunganui College. The video makes connections between contemporary writing and the rich variety of Maori oral literature, for example waiata (songs) whakapapa (genealogy), tauparapara (chants) and pakiwaitara (story telling). The video makes connections also between writing and other material forms of recording and transmitting knowledge such as whakairo (carving), and raranga (weaving). It shows how teachers can motivate children to write by increasing their knowledge and experience with the physical environment, drawing on both traditional and contemporary Maori stories and events.

The video provides examples in Maori of good practice in the teaching of writing. Teachers and students working in tuakana-teina (tutor-tutee) pairs engage in whakaputa whakaaro (brainstorming) and kohikohinga (word-grouping techniques), prior to writing their stories. Also, parents, kaumatua and kuia demonstrate a procedure known as tuhi-atu tuhi-mai, whereby students regularly receive written content feedback (Jerram, Glynn, \& Tuck, 1988). A supportive reader who has a positive relationship with the writer acts as an "audience" and responds, in writing, to the thoughts, ideas, feelings or messages conveyed by the writer. This type of feedback does not focus directly on correction of language structures or spelling, although the responders may well model a correct version of a specific structure used by the student in their writing back to that student. We are now exploring a means of assessing the quality of students' writing, by means of holistic ratings of each sample by groups of Maori teachers, kaumatua, parents and students. We have been careful to involve teachers and kaumatua in devising these assessment procedures.

\section{Training of Maori Resource Teachers (Guidance and Learning)}

This project focuses on cultural issues arising in the work of two itinerant Maori resource teachers (Guidance and Learning). These teachers are responsible for assisting staff in 14 local schools to meet the behavioural and learning needs of Maori students. In all of these schools Maori students comprise at least 25 percent of enrolments. Ten of these schools were mainstream schools and four were Maori medium schools. Two of the Maori medium schools were kura kaupapa Maori. Data were collated from each school on the proportion of Maori teachers and support staff, on Maori content taught within the curriculum, on resources available to assist Maori students, and on the nature of any extended family support systems in place.

Among the findings from this project are that all schools had some form of Maori language and cultural content in the curriculum, ranging from one to two hours per week of Maori enrichment through to varying numbers of bilingual and immersion classes, and kapa haka (cultural performance) groups. However when considering the visibility of Maori culture and society across the entire school curriculum it appeared that much of the input related to traditional myths, legends and Maori cultural practices from pre-European times. While the inclusion of traditional material is important, it is of concern that contemporary Maori society and culture received considerably less emphasis. 
All schools with Maori medium classes and programmes requested urgent assistance with the assessment of literacy. The two Maori resource teachers were able to respond to this need by training teachers in the use of Nga Kete Korero, a framework for placing Maori language texts in order of difficulty (Te Puni Kokiri, 1996). They also provided training in strategies for the assessment of reading and writing in Maori and the collaborative development of schoolwide reading in Maori assessment packages (Glynn et al., 1997).

The project also found that schools had a very low level of liaison with iwi agencies, and most of them were unaware of the services provided for Maori students and families by the various Maori agencies that operated in their communities. One year after the appointment of the two Maori resource teachers, most schools had dramatically increased their level of contact with iwi and other community agencies. A total of 21 contacts were reported over 14 schools during a ten week period in 1996. This increased to 165 contacts over a similar ten week period in 1997.

A systematic analysis of a sample of the casework and interventions initiated within the schools by the two resource teachers is also being undertaken. This analysis will establish the range of behavioural and learning difficulties encountered by Maori students in mainstream and Maori medium schools, and identify culturally appropriate strategies for dealing with these difficulties. So far the study suggests that what really made a difference in assisting Maori students is the resource teachers' facility in identifying students' tribal affiliation, and networking with key elders and support people within the Maori community. Whakawhanaungatanga (establishing and strengthening networks) has emerged as a powerful intervention strategy in itself as it leads to providing students with whanau support in helping overcome both school-based and home-based problems. The process of whakawhanaungatanga within a school can also help promote the Treaty of Waitangi principle of tino rangatiratanga ( self determination) through creating opportunities for Maori to take responsibility for the wellbeing and achievement of Maori students within each school.

The research prioritised tasks and goals which the two itinerant resource teachers needed to address in order to assist each school to meet the behavioural and learning needs of its Maori students. These data, together with the Maori resource teachers' experiences in identifying and overcoming the barriers faced by Maori students and teachers will contribute to a nationwide Special Education initiative,
Special Education 2000 (Ministry of Education, 1997). Part of this initiative involves the training of over 700 resource teachers (Behaviour and Learning) who will assist their own schools to meet the needs of students with mild to moderate behaviour and learning difficulties. It is critical that the training programme for all of these teachers should prepare them with specific information and strategies that will enable them to learn how to be more effective in working with Maori. For example, the process of whakawhanungatanga has emerged as an essential cultural element which needs to be addressed in the training of educators who aspire to work with Maori students.

\section{Mauri Tau}

Several generations of colonisation within Aotearoa have meant that many Maori parents do not have a Maori perspective on human development, and are often overpowered by theories and practices which come from an assimilationist perspective. They themselves are likely to have been raised by members of a generation who lost much of their own language and culture and who are therefore no longer able to pass on these teachings to their children and grand-children. Intercultural marriages have also contributed to this loss of cultural knowledge and understanding.

As parents, young Maori are being increasingly challenged by children of all ages who are experiencing behavioural and learning difficulties at home and school. The level of truancy, suspension and expulsion from the school system is a growing concern, especially as it appears that Maori students are over-represented among this group. There is also the anxiety that some children may be experiencing the effects of intergenerational cycles of disadvantage. Parents of students who are displaying challenging behaviours and low achievement may themselves have displayed challenging behaviours and low achievement during their own schooling. When faced with these challenges, the majority of today's Maori parents look for solutions from within their own childhood or from monocultural mainstream parenting programmes. However, it is no longer appropriate or sufficient to continue to accept and adopt culturally inadequate programmes to address challenges arising within the Maori community.

In response to these challenges, the Poutama Pounamu research whanau have worked in collaboration with Tuhoe Hauora to produce a parenting resource known as Mauri Tau. This resource endeavours to 
recapture traditional Maori knowledge about human development from the time of conception, and about successful parenting practices. Five traditional stories have been drawn on, together with knowledge and traditions from kaumatua, to build the Mauri Tau training procedures and resources. The stories and messages have been presented visually and aurally, using a range of art forms including traditional story telling, drama, song, music, movement, haka, waiata a ringa (action songs) and static art. The training resources were also developed in close collaboration with the two main target groups, young Maori parents and potential parents, namely, adolescent students.

Both traditional and contemporary Maori experts contributed answers to young people's queries about the changes which happen to them at puberty and which all too often lead to unintended and solo pregnancies. Mauri Tau provides these young Maori women who are pregnant with an understanding about what is happening to them, and of the meaning of their new role, from within a Maori cultural perspective. Mauri Tau aims to make the experience of pregnancy an opportunity to learn not just physical health practices from a Western European perspective but also to learn how the whole process of pregnancy and childbirth is understood and valued within the Maori world. Pregnancy and childbirth may be a way to re-connect young people with their Maori identity and tikanga (cultural practices).

\section{Cultural Safety Issues Within the Research Whanau}

As we look back on our own learning in these five projects, we can now fully appreciate the importance of cultural principles in research which aims to improve the achievement of Maori students. These principles which will continue to ensure the safety and wellbeing of Poutama Pounamu Research Whanau, and inform our practice, are:

Kaupapa Maori: All of our research and training activities have been carried out in contexts which have been culturally appropriate and safe for Maori. This has been achieved through our being invited onto several marae and kura kaupapa where the research projects have been supported and facilitated. Decision-making and planning have received kaumatua approval, and our major meetings, workshops and presentations have been conducted according to Maori protocol. In this way, the research and development work in these five projects has remained in the hands of Maori, and has not been taken over by non-Maori interests. Kaupapa Maori principles have also provided a safe space in which non-Maori researchers who understand Maori language and respect these cultural principles can work effectively alongside Maori.

Participation of kaumatua: Our elders have been active participants throughout this research journey. They have given us their authority, blessing and spiritual guidance. They have assisted us through their extensive community networks and through their continued attendance and support at all important occasions, including national and international presentations of our work. They have provided us with excellent role models of tiaki (caring and guidance) manaaki (support and hospitality), and aroha ki te tangata (service to people). They have also been a continual source of energy which has helped us all to continue, especially in the face of difficulties. In return, it is vital that we researchers take full responsibility for our kaumatua, including travel, accommodation and other expenses when costing research proposals.

Working as a whanau: We function as a metaphoric whanau, despite living in different parts of the country, and despite our different ethnicity we have tried to follow appropriate kawa (protocol) in our formal meetings, and in our interactions with Maori and non-Maori visitors. Each of us endeavours to support the wellbeing of the others as well as to work towards attaining the research and development goals we set. Our major decisions are reached through negotiation and consensus. We acknowledge each other's individual experience, expertise and professional networks in finding the best way to reach our collective goals and objectives. Our whanau is strengthened through a relationship built on mutual trust and respect. Each of us is aware that our membership within the whanau carries with it both rights and responsibilities towards each other and towards the whanau as a whole.

Whakawhanaungatanga as a research process: From a Maori perspective, establishing whakapapa links (genealogical or family relationships), or "connecting" oneself with new people one meets is a pervasive and important cultural practice. Maori people will spend considerable time in searching for common tribal relationships and family connections before getting down to business or discussing any set agenda. Knowing who people are and where they have come from is more important than knowing what specific experiences and skills they have. There is a great deal of security and comfort in knowing that we have found a whakapapa link with people we need to work with. 
As our research projects have progressed, we have become aware of how we have expanded our networks, and formed working relationships with more and more people in order to achieve our research objectives. This process of networking has contributed greatly to advancing our research as it has brought more and more people "on board the canoe", strengthening the whanau, and in turn strengthening the community. Indeed, for our research whanau, seeking ways to improve the educational achievement of Maori students and renewing and strengthening whanau networks have become tightly interwoven, and form a single whariki.

\section{Notes}

1. Based on an oral presentation at the Organisation for Economic Development and Ministry of Education Conference: Combating Failure at School, Christchurch, February 3, 1998.

\section{References}

Atvars, K., Berryman, M., Glynn, T., \& Harawira, W. (1997). School community iwi liaison research report: Milestone two. Wellington: Ministry of Education.

Bishop, R. (1996a). Addressing issues of self determination and legitimation in kura kaupapa Maori research. In B. Webber (Ed.), He paepae korero: Research perspectives in Maori education (pp. 143-160). Wellington: New Zealand Council for Educational Research.

Bishop, R. (1996b). Collaborative research stories: Whakawhanaungatanga. Palmerston North: Dunmore Press.

Bishop, R., \& Glynn, T. (1992). He kanohi kitea: Conducting and evaluating educational research. New Zealand Journal of Educational Studies, 27(2), 3-13.

Bishop, R., \& Glynn, T. (1997a). Achieving cultural integrity within education in New Zealand. In K. Cushner \& R. Gagliardi (Eds.), International perspectives in intercultural education. New York: Lawrence Earlbaum Associates.

Bishop, R., \& Glynn, T. (1997b). Researching in Maori contexts: An interpretation of participatory consciousness. Journal of Indigenous Studies (in press)

Coolongatta Statement. (1993, December). The Coolongatta statement on indigenous rights in education. Paper presented at the World Indigenous Peoples' Conference, Wollongong.
Glynn, T. (1985). Contexts for independent learning. Educational Psychology, 5(1), 5-15.

Glynn, T. (1995). Pause Prompt Praise: Reading tutoring procedures for home and school partnership. In S. Wolfendale \& K. Topping (Eds.), Family involvement in literacy: Effective partnerships for home and school. London: Cassell.

Glynn, T., Atvars, K., Furlong, M., \& Teddy, N. (1993). From Pause Prompt Praise to Tatari Tautoko Tauawhi: A bicultural process of adaptation. In S. Barratt, M. Gold \& L. Lawn (Eds.), Towards excellence: Providing effective services for learners with special needs. Inaugural Conference of the Special Education Service, Dunedin.

Glynn, T., Atvars, K., Furlong, M., Davies, M., Rogers, S., \& Teddy, N. (1993). Tatari Tautoko Tauawhi: He awhina tamariki ki te panui pukapuka. Some preliminary findings. Wellington: Cultural Justice and Ethics Symposium Report, New Zealand Psychological Society.

Glynn, T., Berryman, M., Bidois, P., Atvars, K., Duffull, T., \& Horne, J. (1997). Involving children in research: The Hei Āwhina Mātua project. Childrenz Issues, 1(1), 17-22.

Glynn, T., Berryman, M., Harawira, W., Bidois, P., \& Atvars, K. (1997). Bilingual behavioural checklists: Initiating a student teacher and parent partnership. Unpublished paper, Poutama Pounamu Education Research Centre, Tauranga.

Glynn, T. Berryman, M. Atvars, K., \& Harawira, W. (1997). Hei Āwhina Mătua. Final Report to the Ministry of Education, Wellington.

Glynn, T., Berryman, M., Bidois, P., Furlong, M., Walker, R., \& Atvars, K. (1996). Bilingual reading gains for tutors and tutees in a Maori language immersion programme. In He Paepae Korero: Research issues in Maori Education. Wellington: New Zealand Council for Educational Research.

Glynn, T., \& Bishop, R. (1995). Cultural issues in educational research: A New Zealand perspective. He Pukenga Korero, 1(1), 37-43.

Glynn, T., \& Glynn, V. (1986). Shared reading by Cambodian mothers and children learning English as a second language: Reciprocal gains. The Exceptional Child, 33(37), 159-172.

Glynn, E. L., McNaughton, S. S., Robinson, V. R., \& Quinn, M. (1979). Remedial reading at home: Helping you to help your child. Wellington: New Zealand Council for Educational Research.

Harawira, W., Stockman, T., Gear, P., Walker, R., Reweti, M., Berryman, M., Atvars, K., Bidois, P., \& Glynn, T. (1996, December). The Poutama Pounamu research whanau: Relationships and outcomes, 
Maori keynotes. New Zealand Association for Research in Education 18th Annual Conference. Nelson: NZARE.

Holmes, J. (1990). Community languages: Researchers as catalysts. Paper presented at the Second National Conference on Community Languages and English for Speakers of Other Languages, Wellington College of Education, Wellington.

Houghton, S., \& Glynn, T. (1993). Peer tutoring of below average secondary school readers with Pause Prompt Praise: Successive introduction of tutoring components. Behaviour Change 10(2), 75-85.

Jerram, H., Glynn, T., \& Tuck, B. (1988). Responding to the message: Providing a social context for children learning to write. Educational Psychology,(1E2), 31-40.

Limbrick, E., McNaughton, S., \& Glynn, T. (1985). Reading gains for under-achieving tutors and tutees in a cross age peer tutoring programme. Journal of Child Psychology and Psychiatry, 26(6), 939-953.

Lovegrove, M. (1966). The scholastic achievement of European and Maori children. New Zealand Journal of Educational Studies, 1(1), 15-39.

Medcalf, J., \& Glynn, T. (1987). Assisting teachers to implement peer-tutored remedial reading using Pause Prompt and Praise procedures. Queensland Journal of Guidance and Counselling, 1(1), $11-23$.

Ministry of Education. (1997). Special Education 2000. Special Education Policy Document. Wellington: Ministry of Education.

Smith, G. (1990). Taha Maori: Pakeha capture. In J. Codd, R. Harker, \& R. Nash (Eds.), Political issues in New Zealand education. Palmerston North: Dunmore Press.

Smith, G. (1995). Whakaoho Whanau. He Pukenga Korero, 1(1), 18-36.

Tang, H. \& Moore, D. (1992). Effect of cognitive and metacognitive pre-reading activities on the reading comprehension of ESL learners. Educational Psychology, 12 (3 \& 4), 315-331.

Tavener, J., \& Glynn, T. (1989). Peer tutoring of reading as a context for learning English as a second language. Language and Reading: An International Journal, 3(1) 1-11.

Te Puni Kokiri. (1996). Nga Kete Korero framework: Teacher handbook. A framework for organising junior Maori reading texts. Wellington: Huia Publishers.

Wheldall, K., \& Mettem, P. (1985). Behavioural peer tutoring: Training 16 year old tutors to employ the Pause Prompt and Praise method with 12 year old remedial readers. Educational Psychology, 5(1), 27-44.
Wong-Fillmore, L. (1991). When learning a second language means losing a first. Early Childhood Research Quarterly, 6, 323-346.

\section{The authors}

Ted Glynn, Professor of Teacher Education, University of Waikato

Rangiwhakaehu Walker (Ngāti Ranginui, Ngai Te Rangi) Kuia, Specialist Education Service Poutama Pounamu Research Centre, Tauranga

Mere Berryman (Ngai Tūhoe) Researcher, Specialist Education Service Poutama Pounamu Research Centre, Tauranga

Kathryn Atvars (Ngai Te Rangi, Ngāti Awa, Ngāti Kahungunu, Ngāti Whare) Researcher, Specialist Education Service Poutama Pounamu Research Centre, Tauranga

Wai Harawira (Ngai Tūhoe) Kaiwhakahaere, Specialist Education Service, Head Office, Wellington

Hone Kaiwai, Kaiwhakahaere, Specialist Education Service, Head Office, Wellington 